\title{
Acalculous Cholecystitis in a Young Adult with Scrub Typhus: A Case Report and Epidemiology of Scrub Typhus in the Maldives
}

\author{
Hisham Ahmed Imad 1,2,*(D), Aishath Azna Ali ${ }^{3}$, Mariyam Nahuza ${ }^{3}$, Rajan Gurung ${ }^{3}$, Abdulla Ubaid ${ }^{3}$, \\ Aishath Maeesha ${ }^{4}$, Sariu Ali Didi ${ }^{4}$, Rajib Kumar Dey ${ }^{4}$, Abdullah Isneen Hilmy ${ }^{4,5}$, Aishath Hareera ${ }^{6}$, \\ Ibrahim Afzal ${ }^{6}$, Wasin Matsee ${ }^{7}\left(\mathbb{D}\right.$, Wang Nguitragool ${ }^{1,8}$, Emi. E. Nakayama ${ }^{2}$ (D) and Tatsuo Shioda ${ }^{2}(\mathbb{D}$
}

Citation: Imad, H.A.; Ali, A.A.; Nahuza, M.; Gurung, R.; Ubaid, A.; Maeesha, A.; Didi, S.A.; Dey, R.K.; Hilmy, A.I.; Hareera, A.; et al. Acalculous Cholecystitis in a Young Adult with Scrub Typhus: A Case Report and Epidemiology of Scrub Typhus in the Maldives. Trop. Med. Infect. Dis. 2021, 6, 208. https:// doi.org/10.3390/tropicalmed6040208

Academic Editor: Charles

E. Rupprecht

Received: 16 November 2021

Accepted: 6 December 2021

Published: 8 December 2021

Publisher's Note: MDPI stays neutral with regard to jurisdictional claims in published maps and institutional affiliations.

Copyright: (c) 2021 by the authors. Licensee MDPI, Basel, Switzerland. This article is an open access article distributed under the terms and conditions of the Creative Commons Attribution (CC BY) license (https:/ / creativecommons.org/licenses/by/ $4.0 /)$.
1 Mahidol Vivax Research Unit, Faculty of Tropical Medicine, Mahidol University, Bangkok 10400, Thailand; wang.ngu@mahidol.edu

2 Department of Viral Infections, Research Institute for Microbial Diseases, Osaka University, Osaka 565-0871, Japan; emien@biken.osaka-u.ac.jp (E.E.N.); shioda@biken.osaka-u.ac.jp (T.S.)

3 Department of Surgery, Indira Gandhi Memorial Hospital, Malé 20002, Maldives; dr.azna@igmh.gov.mv (A.A.A.); dr.mariyamnahuza@igmh.gov.mv (M.N.); dr.rajangurung@igmh.gov.mv (R.G.); dr.ubaid@igmh.gov.mv (A.U.)

4 Department of Medicine, Indira Gandhi Memorial Hospital, Malé 20002, Maldives; dr.aishathmaesha@igmh.gov.mv (A.M.); sariualididi@igmh.gov.mv (S.A.D.); dey@igmh.gov.mv (R.K.D.); hlmabd001@myuct.ac.za (A.I.H.)

5 Gastrointestinal Unit, Department of Medicine, Groote Schuur Hospital, University of Cape Town, Cape Town 7935, South Africa

6 Health Protection Agency, Ministry of Public Health, Malé 20002, Maldives; hareera@health.gov.mv (A.H.); afzal@health.gov.mv (I.A.)

7 Department of Clinical Tropical Medicine, Faculty of Tropical Medicine, Mahidol University, Bangkok 10400, Thailand; wasin.mat@mahidol.edu

8 Department of Molecular Tropical Medicine and Genetics, Faculty of Tropical Medicine, Mahidol University, Bangkok 10400, Thailand

* Correspondence: hishamahmed.ima@mahidol.ac.th or imad@biken.osaka-u.ac.jp; Tel.: +66-631501402

Abstract: Scrub typhus is a neglected tropical disease predominantly occurring in Asia. The causative agent is a bacterium transmitted by the larval stage of mites found in rural vegetation in endemic regions. Cases of scrub typhus frequently present as acute undifferentiated febrile illness, and without early diagnosis and treatment, the disease can develop fatal complications. We retrospectively reviewed de-identified data from a 23-year-old woman who presented to an emergency department with complaints of worsening abdominal pain. On presentation, she appeared jaundiced and toxic-looking. Other positive findings on abdominal examination were a positive Murphey's sign, abdominal guarding and hepatosplenomegaly. Magnetic resonance cholangiopancreatography demonstrated acalculous cholecystitis. Additional findings included eschar on the medial aspect of the left thigh with inguinal regional lymphadenopathy. Further, positive results were obtained for immunoglobulins $\mathrm{M}$ and $\mathrm{G}$, confirming scrub typhus. The workup for other infectious causes of acute acalculous cholecystitis (AAC) detected antibodies against human herpesvirus 4 (Epstein-Barr virus), suggesting an alternative cause of AAC. Whether that represented re-activation of the Epstein-Barr virus could not be determined. As other reports have described acute acalculous cholecystitis in adult scrub typhus patients, we recommend doxycycline to treat acute acalculous cholecystitis in endemic regions while awaiting serological confirmation.

Keywords: acute acalculous cholecystitis; Orientia tsutsgugamushi; scrub typhus; eschar; Epstein-Barr virus; re-activation; clinical manifestation; Maldives

\section{Introduction}

Infectious diseases are well-known as a scourge of wars. Some infamous accounts include endemic typhus during the Franko-Russo war, trench fever in World War I, and 
scrub typhus during World War II [1]. The latter of these, scrub typhus, is caused by the rickettsial species Orientia tsutsugamushi, an intra-cytosolic coccobacillus with three main prototype strains (Karp, Gilliam and Kato) that can inflict disease of varying severities in humans [2].

The earliest description of scrub typhus appears to be an account of "shashitsu" in Chinese literature from 313 AD [3]. Centuries later, the word "tsutsugamushi" was used in Japan to describe a febrile illness following insect exposures. Tsutsugamushi was a feverish delirium associated with regional lymphadenopathy, rash and a pathognomonic cutaneous finding of tache noire or black spot, commonly referred to now as eschar [4].

The skin lesion of eschar is characterized by central necrosis and surrounding erythema with a halo sign [5]. The necrosis results from acidic enzymes channeled through a stylosome, a funnel created by the vector, gaining access via a skin pore or hair follicle [6]. This triggers a host response comprising infiltration of white blood cells into the dermis, causing the peripheral crusting of the scab.

In the Asia-Pacific theater of World War II, stringent vector control measures were employed to protect deployed troops from the parasitic larval stage of a chigger-mite found amongst the vegetation in endemic regions $[7,8]$. Nevertheless, this task proved challenging during the pre-antibiotic era and case fatality reached up to $40 \%$. In 1947, the first cases of successful treatment with chloromycetin were reported from the Malay Peninsula $[9,10]$.

However, despite the modern availability of surefire antibiotics with bacteriostatic properties that stall the bacterium $O$. tsutsugamushi and allow phagocytes to clear up the infection, the disease still occurs after exposure to the vector. Escalating this problem is the geographic expansion of previously restricted endemic regions, and cases clinically compatible with scrub typhus or showing serological evidence have been reported from Chile, the United Arab Emirates and parts of Africa [11-18].

The Maldives is one endemic region for scrub typhus in Asia [5]. The first description of scrub typhus from the Maldives was reported during World War II [8]. The archipelago has a peculiar historical account comprising a six-decade period with absence of the disease ended by re-emergence with 168 cases, including 10 fatalities [19]. Since that re-emergence in the Maldives, sentinel reporting of scrub typhus has shown occurrences throughout the year, with two periodic peaks observed during festive Eid holiday seasons, which falls during the ninth and twelfth months of the lunar calendar [20].

Complications of scrub typhus often involve multiple systems and fatalities are often due to multi-organ dysfunction syndrome [21]. Commonly involved systems include the respiratory, central nervous, cardiovascular, renal, and gastrointestinal systems. However, reports of complications such as pancreatitis, acute cholecystitis, or acalculous cholecystitis in scrub typhus are rare.

First described in 1844 by a surgeon, acute acalculous cholecystitis (AAC) occurs in mainly critically ill geriatric patients. AAC also occurs postoperatively, and in patients requiring medical interventions such as mechanical ventilation or prolonged parenteral nutrition and fasting [22,23]. This pathology accounts for $10 \%$ of all cases of acute cholecystitis and is associated with high morbidity and mortality rates $[24,25]$. The pathophysiology involves inflammation of the gallbladder causing bile stasis and disruption of circulation causing ischemia and necrosis or rupture of the gallbladder, which then involves the peritoneum. In such cases, AAC is associated with infectious etiologies, mainly involving Gram-negative Enterobacteriaceae or Gram-positive spore-forming bacilli [26]. Interestingly, some other pathogens such as Epstein-Barr virus and O. tsutsugamushi have been described to be associated with AAC in otherwise healthy adults [27-38]. Here, we report a case of acute acalculous cholecystitis in a young healthy adult from the Maldives.

\section{Materials and Methods}

The case we describe here presented to Indira Gandhi Memorial Hospital (IGMH) in Malé, Republic of Maldives, in July 2021. De-identified clinical and laboratory data 
during the hospitalization were reviewed using in-patient medical charts. Diagnostics for O. tsutsugamushi included the "Scrub Typhus Detect ${ }^{\mathrm{TM}}$ " immunoglobulin (Ig)M/IgG enzyme-linked immunosorbent assay (InBios International, Seattle, WA, USA). Diagnostics for Epstein-Barr virus included VIDAS®EBV which detected Epstein-Barr viral capsid antigen (EBV-VCA) IgM/IgG, early antigen (EBV-EA) IgG, and nuclear antigen (EBV-NA) IgG by chemiluminescence assays (bioMérieux Italia, Florence, Italy). Hemoculture was performed using an automated culture system (bioMérieux, Durham, NC, USA). We also obtained epidemiological surveillance data for the preceding nine years (2012-2021) on scrub typhus in the Maldives from the Health Protection Agency at the Ministry of Health.

\section{Case Report}

We present the case of a previously healthy 23-year-old woman who presented to the emergency department of IGMH with worsening abdominal pain and fatigue (Figure S1). The presenting complaint was associated with a self-reported 9-day history of high-grade fever accompanied by chills, and displaying a diurnal pattern. Four days before presentation, the patient had consulted a primary-care physician and had been prescribed amoxicillin and clavulanic acid for tonsillopharyngitis. Additional history included several episodes of vomiting with the onset of colicky, non-radiating abdominal pain of severe intensity, without any apparent aggravating or relieving factors. The patient had traveled from her home island of Gadhdhoo, in a southern atoll in the Maldives, to the capital city of Malé to visit friends and relatives a couple of days before falling ill, as illustrated in Figure S2. The annual descriptive epidemiology of scrub typhus in the Maldives is presented in Figure S3.

On examination, the patient was conscious and coherent, but appeared dehydrated, jaundiced, and toxic-looking. Oral temperature was $39^{\circ} \mathrm{C}$, and heart rate was 110 beats $/ \mathrm{min}$ with a mean arterial blood pressure of $73 \mathrm{mmHg}$. Both tonsils were enlarged with evidence of pharyngitis and palpable cervical lymphadenopathy. Evaluations of the cardiovascular, respiratory, and central nervous systems found no abnormalities. Other abdominal examinations revealed a positive Murphy's sign and guarding on palpation of the abdomen. The results of laboratory investigations on presentation are shown in Table 1.

The initial hematological profile on presentation showed lymphocytosis and increased monocytes, although leukocytes, neutrophils, and platelets remained within normal ranges. Hyperbilirubinemia and elevated transaminases were identified from liver function tests. Further, hyperferritinemia and elevated levels of C-reactive protein were identified. Ultrasonography confirmed Murphey's sign from the probe test and demonstrated edema of the gallbladder wall. Computed tomography (CT) of the abdomen revealed hepatosplenomegaly. Magnetic resonance cholangiopancreatography subsequently confirmed acalculous cholecystitis, as shown in Figure 1.

The patient was admitted with parenteral fluids to correct dehydration, broad-spectrum antibiotics (cefotaxime at $2 \mathrm{~g} /$ day, metronidazole at $1500 \mathrm{mg} /$ day), and parenteral analgesics. During nursing care, eschar was noticed on the medial aspect of the left thigh (Figure S4. Left regional inguinal lymphadenopathy was also detected. Doxycycline was started at a loading stat dose of $200 \mathrm{mg}$ followed by $200 \mathrm{mg}$ /day in two divided doses for seven days. Fever cleared within $52 \mathrm{~h}$ of beginning doxycycline (Figure S5. Symptoms of abdominal pain gradually improved, and at the time of discharge from hospital, she had residual signs of fatigue. 
Table 1. Laboratory Results at Presentation and Before Discharge.

\begin{tabular}{|c|c|c|}
\hline Day of Illness (Days) & 9 & 14 \\
\hline Leukocyte/ $\mu \mathrm{L}$ & 6650 & 8030 \\
\hline Neutrophils $/ \mu \mathrm{L}$ & 4788 & 4496 \\
\hline Lymphocytes/ $\mu \mathrm{L}$ & 1349 & 2328 \\
\hline Monocytes $/ \mu \mathrm{L}$ & 435 & 1003 \\
\hline Eosinophils $/ \mu \mathrm{L}$ & 0 & 24 \\
\hline Basophils/ $\mu \mathrm{L}$ & 0 & 0 \\
\hline Platelets $/ \mu \mathrm{L}$ & 269,000 & 545,000 \\
\hline Hemoglobin (g/dL) & 10.6 & 7.8 \\
\hline Hematocrit (\%) & 32.9 & 24.6 \\
\hline Total Bilirubin (mg/dL) & 4.7 & 3.5 \\
\hline Direct Bilirubin (mg/dL) & 3.5 & 2.6 \\
\hline Total protein $(\mathrm{g} / \mathrm{dL})$ & 6.9 & 6.8 \\
\hline Albumin (g/dL) & 3.4 & 2.8 \\
\hline Alkaline phosphatase (IU/L) & 288 & 250 \\
\hline Aspartate aminotransferase (IU/L) & 140 & 76 \\
\hline Alanine aminotransferase (IU/L) & 157 & 93 \\
\hline Creatinine $(\mathrm{mg} / \mathrm{dL})$ & 0.8 & 0.6 \\
\hline Urea $(\mathrm{mg} / \mathrm{dL})$ & 10 & 6.4 \\
\hline $\mathrm{CRP}(\mathrm{mg} / \mathrm{dL})$ & 7.7 & 2.8 \\
\hline Sodium (mmol/L) & 131 & 134 \\
\hline Potassium (mmol/L) & 4.5 & 4.3 \\
\hline Ferritin $(\mathrm{ng} / \mathrm{mL})$ & 1299.3 & \\
\hline LDH (IU/L) & 726 & \\
\hline EBV-VCA IgM (IU/mL) & 63.6 & \\
\hline EBV-VCA IgG (IU/mL) & 89.9 & \\
\hline EBV-EA IgG (IU /mL) & 16.1 & \\
\hline EBV-NA IgG (IU/mL) & 574.0 & \\
\hline Blood culture & & no growth \\
\hline Orientia tsutsugamushi IgM & positive & \\
\hline Orientia tsutsugamushi IgG & positive & \\
\hline
\end{tabular}

CRP: C-reactive protein, LDH: lactate dehydrogenase, EBV-VCA: Epstein-Barr virus viral capsid antigen, EBV-EA Epstein-Barr virus early antigen, EBV-NA: Epstein-Barr virus nuclear antigen, IgM: immunoglobulin M, IgG: immunoglobulin G.

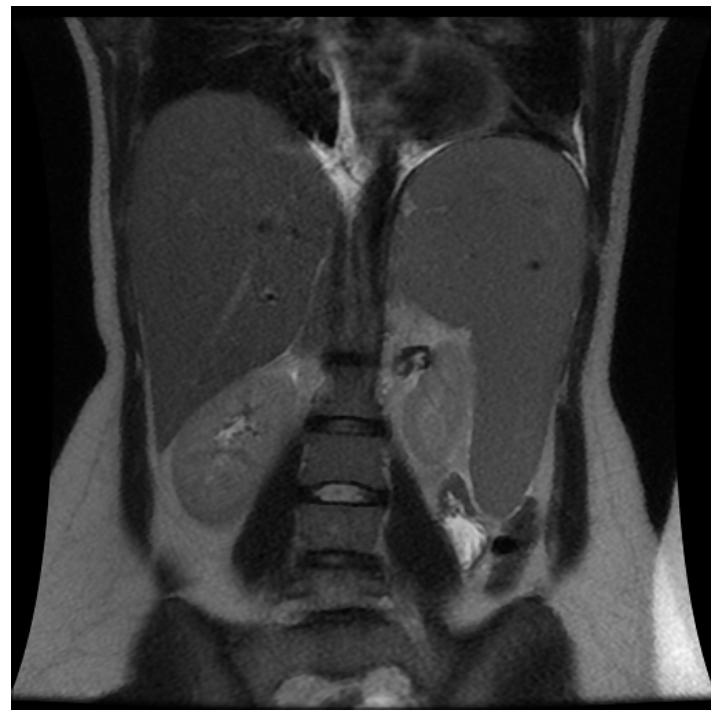

(a)

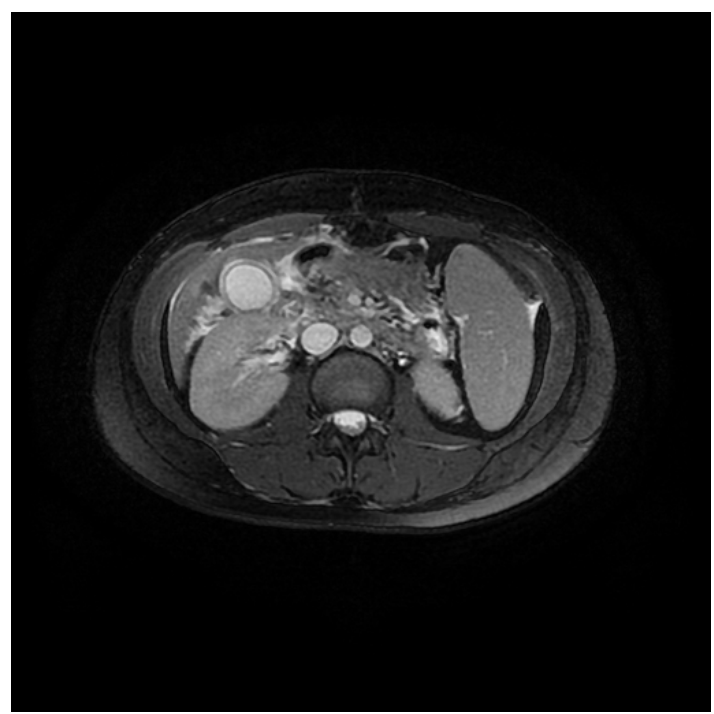

(b)

Figure 1. Cont. 


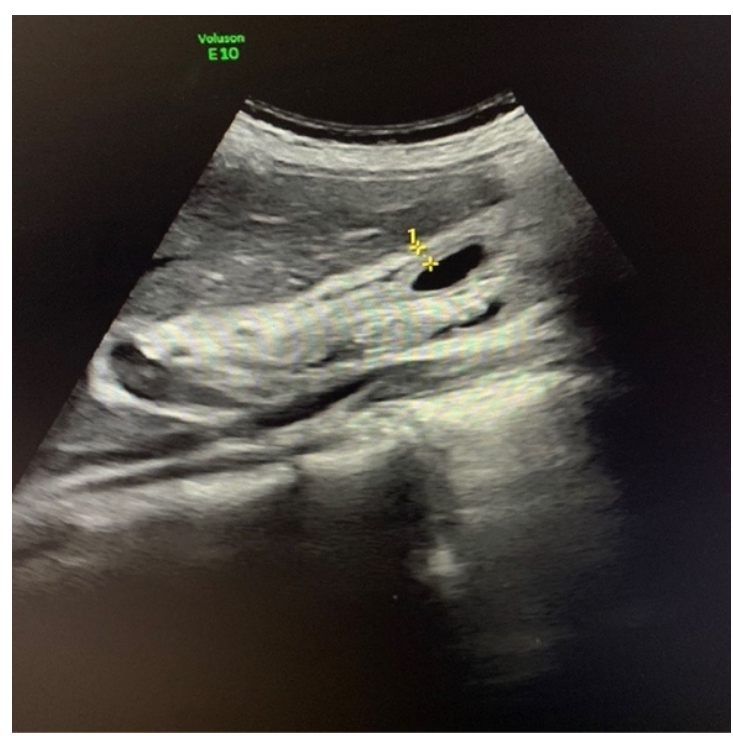

(c)

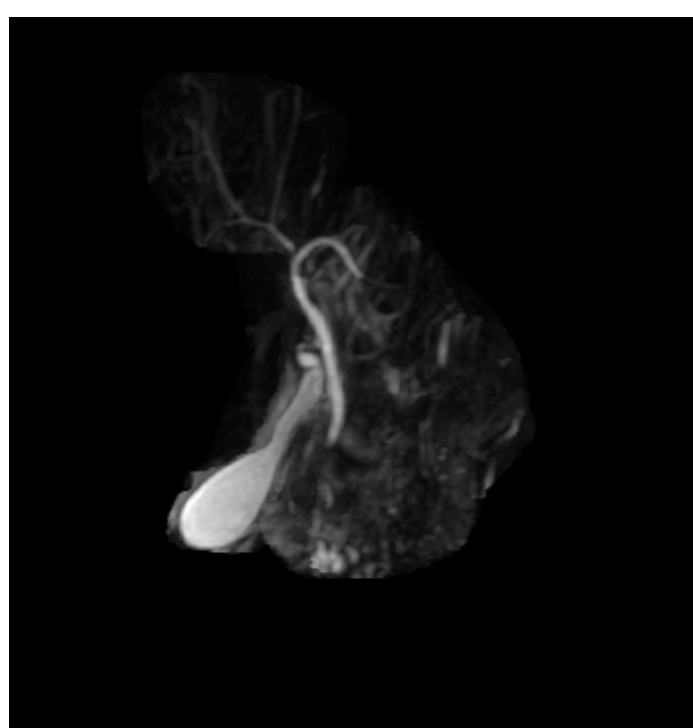

(d)

Figure 1. Imaging of the abdomen during hospitalization. (a) Coronal-view CT of the abdomen shows hepatosplenomegaly. (b) Axial-view CT of the abdomen demonstrates cholecystitis with enhancement of the gallbladder wall. (c) Longitudinal ultrasonography depicts an edematous gallbladder wall (wall thickness $>4 \mathrm{~mm}$ ) without lithiasis. (d) Magnetic resonance cholangiopancreatography reveals a ballooned gallbladder without any ductal obstruction, but with signs of inflammation consistent with acalculous cholecystitis.

\section{Discussion}

In the Maldives, scrub typhus was simply forgotten until its sudden re-emergence in $2002[5,19,39]$. Since decades of sentinel data reflect the existence of $O$. tsutsugamush $i$ throughout the archipelago, reports of scrub typhus from Faafu, Vaavu, and Meemu atolls are recent. We loosely associate this peculiar finding with urbanization, which could have exposed individuals to areas of vegetation where the vector is found [5].

The incubation of scrub typhus is 6-21 days [21]. Consequently, when obtaining a travel history, a minimum of three weeks is necessary to consider scrub typhus among the differential diagnoses. Clinical manifestations of scrub typhus commonly appear first as undifferentiated febrile illness. During the early phase of disease, systemic symptoms are predominantly present without localizing foci of infection. Nevertheless, our patient presented with intermittent fever and she had complaints of sore throat and documented findings of tonsillopharyngitis from her initial visit to the primary-care physician. Similar manifestations had previously been described in scrub typhus patients, where misdiagnosis unfortunately led to complications from scrub typhus [40].

Gastrointestinal (GI) symptoms occur in scrub typhus, but less frequently compared to systemic symptoms [41]. GI symptoms were reported in $20-76 \%$ of scrub typhus cases, with varying severity $[42,43]$. As described in one cohort, the most common GI symptom was nausea, followed by abdominal pain, vomiting, and diarrhea [41]. The patient in the present case developed nausea during the third day after symptoms onset and experienced several episodes of vomiting with bile contents, up until the abdominal pain started. A correlation between endoscopic findings suggestive of gastrointestinal vasculitis and disease severity has previously been demonstrated [43]. O. tsutsugamushi shows tropism to several host cells, including endothelial cells with the pathogenicity of endotheliitis [44]. Dissemination occurs within macrophages, and the bacterium has previously been detected in several organs, including in the human gallbladder [45].

Other studies have previously described hepatosplenomegaly, gallbladder or periportal edema and abdominal lymphadenopathy as GI findings visualized in patients with scrub typhus [46]. In the same cohort, splenomegaly was detected in 15 of 19 cases and $16 \%$ developed splenic infarcts due to acute enlargement of the spleen. The patient in 
our case presented also exhibited massive splenomegaly but, fortunately, no splenic infarcts developed. In addition, the liver was enlarged. Animal studies have demonstrated hepatomegaly resulting from periportal inflammation [47]. Similarly, thickening of the gallbladder wall can result from perivasculitis or vasculitis [32]. The hyperbilirubinemia observed in the presented case was likely due to vasculitis and hepatitis from 0 . tsutsugamushi as previously described $[31,48]$. Nevertheless, as there was no biopsy performed, we could not demonstrate the histopathological changes compatible with cholestatic hepatitis. Presentation with acute abdomen in cases of scrub typhus is rare, but does occur as in this case, and has on occasion resulted in explorative surgeries [49].

The patient in this case showed the triad of fever, right upper quadrant pain, and clinical jaundice, suggestive of acute cholecystitis. Nevertheless, some hematological features such as leukocytosis were absent from the hematological profile. In addition, no risk factors for cholecystitis were identified, such as alcohol consumption or evidence of cholelithiasis. With the identification of the eschar during nursing care, scrub typhus was suspected and doxycycline was started, and the fever cleared within two days. Other antibiotics commonly used to treat scrub typhus are chloramphenicol and azithromycin, with alternative drugs such as rifampin as a second-line agent in tuberculosis endemic regions [50]. The patient was discharged from hospital five days later, once the abdominal pain had completely subsided. We were unable to obtain follow-up images showing resolution of gallbladder wall edema or a clinical specimen for molecular confirmation of O. tsutsugam ushi, due to the retrospective nature of this report.

In tropical regions, coinfections with other tropical diseases are often observed, obfuscating the clinical characteristics of diseases [51]. This provides a major impediment to correct clinical judgment and often results in a poor clinical trajectory with missed diagnoses [52]. It has been previously reported that $15 \%$ of scrub typhus cases had coinfection with other diseases [53]. Identifying coinfections is an important challenge for clinicians, as some are treatable diseases such as influenza, malaria, leptospirosis, typhoid or melioidosis [54-63]. Others have described severe manifestation in scrub typhus co-infected with dengue and other viral infections [64-68].

Interestingly, EBV was also detected from serology, and these results should be interpreted carefully. The patients showed several features consistent with primary mononucleosis, including tonsillopharyngitis, adenopathy, hepatosplenomegaly, and lymphocytosis. In addition, no eruption of rash was identified in this case, as previously described [69]. We could not determine the percentage increase in atypical lymphocytes, which would have helped distinguish primary mononucleosis from reactivation [70]. Reactivation is frequently overserved with individuals with primary or secondary immunodeficiency states [71]. Further, reactivation of EBV from other intracellular bacteria and viruses has previously been described [72,73]. Nevertheless, others have also reported mononucleosislike features in scrub typhus [74]. As mentioned in the Introduction, EBV infection can also complicate and manifest as acute cholecystitis without lithiasis. During the lytic phase, the virus can replicate in tonsillar tissues and hepatocytes and manifest with splenomegaly. We wondered whether O. tsutsugamushi could trigger the activation of latent EBV and whether reactivation of B-lymphotrophic oncogenic viruses such as EBV pose a risk for the development of malignancies [75].

Scrub typhus is a neglected tropical disease and a public health concern. Increasing public awareness regarding prevention and educating clinicians beginning work in endemic regions about scrub typhus, among other common tropical diseases, could help detect cases, start treatment in a timely manner, and prevent complications and death [76].

In conclusion, scrub typhus can complicate and manifest as acute acalculous cholecystitis in young adults. Therefore, we recommend using doxycycline empirically in cases presenting from regions endemic for scrub typhus, providing no contraindications are present. 
Supplementary Materials: The following are available online at https:/ / www.mdpi.com/article/10 .3390 / tropicalmed6040208/s1. Figure S1. Timeline depicting the clinical course prior to hospitalization; Figure S2. Past and recent epidemiology of scrub typhus in atolls of the Maldives; Figure S3. Two decades of sentinel reporting of scrub typhus in the Maldives; Figure S4. Eschar lesion on the medial aspect of the thigh; and Figure S5. Clinical course during hospitalization.

Author Contributions: Conceptualization, A.A.A., H.A.I., W.N., E.E.N. and T.S.; methodology, H.A.I., W.N., W.M., E.E.N. and T.S.; software, H.A.I.; validation A.A.A., M.N., R.G., A.U., A.M., S.A.D., R.K.D., A.I.H., A.H., I.A., W.M., W.N., E.E.N. and T.S.; formal analysis, H.A.I., A.A.A., M.N., R.G., A.U., A.M., S.A.D., R.K.D., A.I.H., A.H., I.A., W.M., W.N., E.E.N. and T.S.; investigation, H.A.I., A.A.A., M.N., A.M., resources, A.A.A., M.N., R.G., A.U., A.M., S.A.D., R.K.D., A.I.H., A.H., I.A., W.M., W.N., E.E.N. and T.S.; data curation, H.A.I.; M.N., A.M., writing—original draft preparation, H.A.I., W.N., E.E.N. and T.S.; writing-review and editing, H.A.I., A.A.A., M.N., R.G., A.U., A.M., S.A.D., R.K.D., A.I.H., A.H., I.A., W.M., W.N., E.E.N. and T.S.; visualization, H.A.I.; supervision, A.U., W.N., E.E.N. and T.S.; project administration, H.A.I., A.A.A., M.N., R.G., A.U., A.M., S.A.D., R.K.D., A.I.H., A.H., I.A., W.M., W.N., E.E.N. and T.S. All authors have read and agreed to the published version of the manuscript.

Funding: This study was funded by the Japan Agency for Medical Research and Development (AMED, grant numbers JP19m0108003 and 21wm0225010h0102), with support from the Osaka University ASEAN campus project and the International Postdoctoral Fellowship 2021, Mahidol University through W.N. and H.A.I.

Institutional Review Board Statement: The reporting of this case was conducted in accordance with the guidelines of the Declaration of Helsinki. An exemption to ethical approval was granted on 29 September 2021 (Ref: 137-B(NHA)/MISC /2021/045) by the National Healthcare Academy at Indira Gandhi Memorial Hospital, Malé, Republic of Maldives.

Informed Consent Statement: Informed consent was obtained from the patient involved in the study.

Data Availability Statement: The data presented in this study are available on request from the corresponding author. The data are not publicly available to ensure the privacy of the study participant.

Acknowledgments: We are sincerely grateful to the patient who volunteered to be part of this report and all staff at the Department of Surgery, particularly the wonderful nurses and surgical officers who cared for this patient. In addition, we are thankful to the Director of Medical Services, Shan Saeed, and Ibrahim Saleem, at Indira Gandhi Memorial Hospital. The authors would like to express their deepest gratitude to Jetsumon Prachumsri, Mahidol Vivax Research Unit, Faculty of Tropical Medicine, Mahidol University, for her administrative support, guidance, and constant encouragement.

Conflicts of Interest: The authors declare no conflict of interest.

\section{References}

1. Paris, D.H. Special Issue "The Past and Present Threat of Rickettsial Diseases". Trop. Med. Infect. Dis. 2020, 5, 187. [CrossRef]

2. Kelly, D.J.; Fuerst, P.A.; Richards, A.L. Origins, Importance and Genetic Stability of the Prototype Strains Gilliam, Karp and Kato of Orientia tsutsugamushi. Trop. Med. Infect. Dis. 2019, 4, 75. [CrossRef]

3. Richards, A.L.; Jiang, J. Scrub Typhus: Historic Perspective and Current Status of the Worldwide Presence of Orientia Species. Trop. Med. Infect. Dis. 2020, 5, 49. [CrossRef]

4. Nagayo, M.; Miyagawa, Y.; Mitamura, T.; Imamura, A. On the Nymph and Prosopon of the Tsutsugamushi, Leptotrombidium Akamushi, N. Sp. (Trombidium Akamushi Brumpt), Carrier of the Tsutsugamushi Disease. J. Exp. Med. 1917, 25, $255-272$. [CrossRef] [PubMed]

5. Imad, H.A.; Tanyaratsrisakul, S.; Piyaphanee, W.; Wattanagoon, Y. Skin lesion from Maldives: Classic but forgotten. Travel Med. Infect. Dis. 2017, 17, 74-75. [CrossRef] [PubMed]

6. Hase, T.; Roberts, L.W.; Hildebrandt, P.K.; Cavanaugh, D.C. Stylostome Formation by Leptotrombidium Mites (Acari: Trombiculidae). J. Parasitol. 1978, 64, 712. [CrossRef] [PubMed]

7. Megaw, J.W.D. Scrub Typhus as a War Disease. BMJ 1945, 2, 109-112. [CrossRef] [PubMed]

8. Philip, C.B. Tsutsugamushi disease in World War II. J. Parasitol. 1948, 34, 169-191. [CrossRef]

9. Luce-Fedrow, A.; Lehman, M.L.; Kelly, D.J.; Mullins, K.; Maina, A.N.; Stewart, R.L.; Ge, H.; John, H.S.; Jiang, J.; Richards, A.L. A Review of Scrub Typhus (Orientia tsutsugamushi and Related Organisms): Then, Now, and Tomorrow. Trop. Med. Infect. Dis. 2018, 3, 8. [CrossRef]

10. Giles, H.M.; Symington, T. Chloromycetin in scrub-typhus. Lancet 1950, 255, 16-19. [CrossRef] 
11. Weitzel, T.; la Fuente, M.C.S.-D.; Martínez-Valdebenito, C.; Stekolnikov, A.A.; Pérez, C.; Pérez, R.; Vial, C.; Abarca, K.; AcostaJamett, G. Novel Vector of Scrub Typhus in Sub-Antarctic Chile: Evidence from Human Exposure. Clin. Infect. Dis. 2021. [CrossRef]

12. Izzard, L.; Fuller, A.; Blacksell, S.D.; Paris, D.H.; Richards, A.L.; Aukkanit, N.; Nguyen, C.; Jiang, J.; Fenwick, S.; Day, N.P.J.; et al. Isolation of a novel Orientia species (O. chuto sp. nov.) from a patient infected in Dubai. J. Clin. Microbiol. 2010, 48, 4404-4409. [CrossRef]

13. Ghorbani, R.P.; Ghorbani, A.J.; Jain, M.K.; Walker, D.H. A Case of Scrub Typhus Probably Acquired in Africa. Clin. Infect. Dis. 1997, 25, 1473-1474. [CrossRef]

14. Osuga, K.; Kimura, M.; Goto, H.; Shimada, K.; Suto, T. A case of tsutsugamushi disease probably contracted in Africa. Eur. J. Clin. Microbiol. Infect. Dis. 1991, 10, 95-96. [CrossRef] [PubMed]

15. Horton, K.C.; Maina, A.; Dueger, E.; Pimentel, G.; Jiang, J.; Richards, A.L.; Zayed, A.; Ahmed, A.A. Evidence of Rickettsia and Orientia Infections among Abattoir Workers in Djibouti. Am. J. Trop. Med. Hyg. 2016, 95, 462-465. [CrossRef] [PubMed]

16. Thiga, J.W.; Mutai, B.K.; Eyako, W.K.; Ng'Ang'A, Z.; Jiang, J.; Richards, A.L.; Waitumbi, J.N. High Seroprevalence of Antibodies against Spotted Fever and Scrub Typhus Bacteria in Patients with Febrile Illness, Kenya. Emerg. Infect. Dis. 2015, $21,688-691$. [CrossRef]

17. Masakhwe, C.; Linsuwanon, P.; Kimita, G.; Mutai, B.; Leepitakrat, S.; Yalwala, S.; Abuom, D.; Auysawasi, N.; Gilbreath, T.; Wanja, E.; et al. Identification and Characterization of Orientia chuto in Trombiculid Chigger Mites Collected from Wild Rodents in Kenya. J. Clin. Microbiol. 2018, 56, e01124-18. [CrossRef]

18. Yen, T.-Y.; Zhang, Z.; Chao, C.-C.; Ching, W.-M.; Shu, P.-Y.; Tseng, L.-F.; Carvalho, A.V.D.A.; Tsai, K.-H. Serologic Evidence for Orientia Exposure in the Democratic Republic of Sao Tome and Principe. Vector-Borne Zoonotic Dis. 2019, 19, 821-827. [CrossRef]

19. Lewis, M.D.; Yousuf, A.A.; Lerdthusnee, K.; Razee, A.; Chandranoi, K.; Jones, J.W. Scrub typhus reemergence in the Maldives. Emerg. Infect. Dis. 2003, 9, 1638-1641. [CrossRef]

20. Scrub Typhus Surveillance Data; Health Protection Agency, Ministry of Health: Malé, Maldives, 2021.

21. Rajapakse, S.; Weeratunga, P.; Sivayoganathan, S.; Fernando, S.D. Clinical manifestations of scrub typhus. Trans. R. Soc. Trop. Med. Hyg. 2017, 111, 43-54. [CrossRef] [PubMed]

22. Walsh, K.; Goutos, I.; Dheansa, B. Acute Acalculous Cholecystitis in Burns: A Review. J. Burn Care Res. 2018, 39, 724-728. [CrossRef] [PubMed]

23. Hu, S.; Dong, Z.; Wang, C.; Yang, W. Chinese Obesity and Metabolic Surgery Collaborative. Acute Gangrenous Acalculous Cholecystitis After Laparoscopic Roux-en-Y Gastric Bypass: A Case Report. Obes. Surg. 2021, 1-2. [CrossRef]

24. Shapiro, M.J.; Luchtefeld, W.B.; Kurzweil, S.; Kaminski, D.L.; Durham, R.M.; Mazuski, J.E. Acute acalculous cholecystitis in the critically ill. Am. Surg. 1994, 60, 335-339. [PubMed]

25. McChesney, J.A.; Northup, P.G.; Bickston, S.J. Acute Acalculous Cholecystitis Associated with Systemic Sepsis and Visceral Arterial Hypoperfusion: A Case Series and Review of Pathophysiology. Dig. Dis. Sci. 2003, 48, 1960-1967. [CrossRef]

26. Markaki, I.; Konsoula, A.; Markaki, L.; Spernovasilis, N.; Papadakis, M. Acute acalculous cholecystitis due to infectious causes. World J. Clin. Cases 2021, 9, 6674-6685. [CrossRef]

27. Reed, A.C. Scrub Typhus. Cal. West Med. 1944, 61, 62-63.

28. Wang, N.-C.; Ni, Y.-H.; Peng, M.-Y.; Chang, F.-Y. Acute acalculous cholecystitis and pancreatitis in a patient with concomitant leptospirosis and scrub typhus. J. Microbiol. Immunol. Infect. 2003, 36, 285-287.

29. Hayakawa, K.; Oki, M.; Moriya, Y.; Mizuma, A.; Ohnuki, Y.; Yanagi, H.; Fukuda, R.; Ozawa, H.; Takizawa, S.; Takagi, A. A case of scrub typhus with acalculous cholecystitis, aseptic meningitis and mononeuritis multiplex. J. Med. Microbiol. 2012, 61, 291-294. [CrossRef]

30. Lee, H.; Ji, M.; Hwang, J.-H.; Lee, J.-Y.; Lee, J.-H.; Chung, K.M.; Lee, C.-S. Acute Cholecystitis in Patients with Scrub Typhus. J. Korean Med. Sci. 2015, 30, 1698-1700. [CrossRef]

31. Lee, S.J.; Cho, Y.H.; Lee, S.Y.; Jeong, D.W.; Choi, E.J.; Kim, Y.J.; Lee, J.G.; Lee, Y.H. A Case of Scrub Typhus Complicated by Acute Calculous Cholecystitis. Korean J. Fam. Med. 2012, 33, 243-246. [CrossRef]

32. Charoenphak, S.; Rattanawong, P.; Sungkanuparph, S. Acute Cholecystitis as an Unusual Presentation of Scrub Typhus: A Report of Two Cases and Review of The Literature. S. Asian J. Trop. Med. Public Health 2017, 48, 143-149.

33. Acharya, S.; Yadav, J.K.; Khanal, N.; Bhandari, R.; Ghimire, B. Acute Severe Calculous Cholecystitis with Multiorgan Failure Complicated by Scrub Typhus. Case Rep. Surg. 2019, 2019, 1-4. [CrossRef]

34. Gagneux-Brunon, A.; Suy, F.; Pouvaret, A.; Pillet, S.; Tarantino, E.; Bouchet, D.; Fresard, A.; Cazorla, C.; Guglielminotti, C.; Lucht, F.; et al. Acute acalculous cholecystitis, a rare complication of Epstein-Barr virus primary infection: Report of two cases and review. J. Clin. Virol. 2014, 61, 173-175. [CrossRef]

35. Aydin Teke, T.; Tanir, G.; Ozel, A.; Timur, O.M.; Eksioglu, A.S. A case of acute acalculous cholecystitis during the course of reactive Epstein-Barr virus infection. Turk. J. Gastroenterol. 2013, 24, 571-572. [CrossRef]

36. Vermaak, J.S. Epstein-Barr virus acute acalculous cholecystitis. Can. Med. Assoc. J. 2021, 193, E1143. [CrossRef] [PubMed]

37. Harvey, K.G.; Tice, J.G.; Sigal, A. Epstein-Barr Virus Causing Clinical Jaundice and Acute Acalculous Cholecystitis in a Previously Healthy 17-Year-Old Girl. Am. J. Case Rep. 2021, 22, e932285. [CrossRef] [PubMed]

38. Nakagawa, H.; Miyata, Y. Epstein-Barr virus infection associated with acute acalculous cholecystitis in a 20-year-old woman. Can. Med. Assoc. J. 2021, 193, E696. [CrossRef] 
39. Wolstenholme, R.J. The disease spectrum in a Maldivian (Adduan) population. Trans. R. Soc. Trop. Med. Hyg. 1984, 78, 505-507. [CrossRef]

40. Kang, N.; Lan, N.; Ye, H. Clinical analysis of tsutsugamushi disease misdiagnosed as tonsillitis. Lin Chuang Er Bi Yan Hou Tou Jing Wai Ke Za Zhi J. Clin. Otorhinolaryngol. Head Neck Surg. 2014, 28, 425-426.

41. Lee, J.-H.; Lee, J.; Chung, K.M.; Kim, E.S.; Kwak, Y.G.; Moon, C.; Lee, C.-S. Dynamics of Clinical Symptoms in Patients with Scrub Typhus. Jpn. J. Infect. Dis. 2013, 66, 155-157. [CrossRef]

42. Aung, T.; Supanaranond, W.; Phumiratanaprapin, W.; Phonrat, B.; Chinprasatsak, S.; Ratanajaratroj, N. Gastrointestinal manifestations of septic patients with scrub typhus in Maharat Nakhon Ratchasima Hospital. S. Asian J. Trop. Med. Public Health 2004, 35, 845-851.

43. Lee, J.; Kim, D.-M.; Yun, N.R.; Kim, Y.D.; Park, C.G.; Kim, M.W. The Correlation of Endoscopic Findings and Clinical Features in Korean Patients with Scrub Typhus: A Cohort Study. PLoS ONE 2016, 11, e0155810. [CrossRef] [PubMed]

44. Moron, C.G.; Popov, V.L.; Feng, H.-M.; Wear, D.; Walker, D.H. Identification of the Target Cells of Orientia tsutsugamushi in Human Cases of Scrub Typhus. Mod. Pathol. 2001, 14, 752-759. [CrossRef] [PubMed]

45. Lee, Y.; Kim, S.I.; Yi, Y.-S.; Lee, H.; Hwang, J.-H.; Park, E.C.; Jun, S.; Lee, C.-S. Transmission Electron Microscopy Confirmation of Orientia tsutsugamushi in Human Bile. Emerg. Infect. Dis. 2020, 26, 3101-3103. [CrossRef]

46. Jeong, Y.J.; Kim, S.; Wook, Y.D.; Lee, J.W.; Kim, K.-I.; Lee, S.H. Scrub Typhus: Clinical, Pathologic, and Imaging Findings. RadioGraphics 2007, 27, 161-172. [CrossRef] [PubMed]

47. Keller, C.A.; Hauptmann, M.; Kolbaum, J.; Gharaibeh, M.H.; Neumann, M.; Glatzel, M.; Fleischer, B. Dissemination of Orientia tsutsugamushi and Inflammatory Responses in a Murine Model of Scrub Typhus. PLoS Negl. Trop. Dis. 2014, 8, e3064. [CrossRef]

48. Lee, K.H.; Heo, S.T.; Jeong, S.U.; Kim, M.-Y.; Jeong, W.S.; Hyun, C.L.; Kim, Y.-K.; Yoo, J.R. Acute Cholangitis Caused by Boryong Strain of Orientia tsutsugamushi. Infect. Chemother. 2020, 52, 621-625. [CrossRef]

49. Yang, C.H.; Young, T.G.; Peng, M.Y.; Hsu, G.J. Unusual presentation of acute abdomen in scrub typhus: A report of two cases. Zhonghua Yi Xue Za Zhi (Taipei) 1995, 55, 401-404.

50. El Sayed, I.; Liu, Q.; Wee, I.; Hine, P. Antibiotics for treating scrub typhus. Cochrane Database Syst. Rev. 2018, 9, CD002150. [CrossRef]

51. Hilmy, A.I.; Dey, R.K.; Imad, H.A.; Yoosuf, A.A.; Nazeem, A.; Latheef, A.A. Coronavirus disease 2019 and dengue: Two case reports. J. Med. Case Rep. 2021, 15, 1-5. [CrossRef]

52. Miqdhaadh, A.; Imad, H.A.; Fazeena, A.; Ngamprasertchai, T.; Nguitragool, W.; Nakayama, E.E.; Shioda, T. Multisystem Inflammatory Syndrome Associated with SARS-CoV-2 Infection in an Adult: A Case Report from the Maldives. Trop. Med. Infect. Dis. 2021, 6, 187. [CrossRef] [PubMed]

53. Brummaier, T.; Kittitrakul, C.; Choovichian, V.; Lawpoolsri, S.; Namaik-Larp, C.; Wattanagoon, Y. Clinical manifestations and treatment outcomes of scrub typhus in a rural health care facility on the Thailand-Myanmar border. J. Infect. Dev. Ctries. 2017, 11, 407-413. [CrossRef]

54. Jhuria, L.; Muthu, V.; Gupta, S.; Singh, M.P.; Biswal, M.; Goyal, K.; Pannu, A.K.; Kumari, S.; Bhalla, A.; Mohindra, R.; et al. Coinfection of H1N1 Influenza and Scrub Typhus-A Review. QJM: Int. J. Med. 2020, 113, 465-468. [CrossRef]

55. Wilairatana, P.; Kuraeiad, S.; Rattaprasert, P.; Kotepui, M. Prevalence of malaria and scrub typhus co-infection in febrile patients: A systematic review and meta-analysis. Parasites Vectors 2021, 14, 1-13. [CrossRef] [PubMed]

56. Ahmad, S.; Dhar, M.; Mittal, G.; Bhat, N.K.; Shirazi, N.; Kalra, V.; Sati, H.C.; Gupta, V. A comparative hospital-based observational study of mono- and co-infections of malaria, dengue virus and scrub typhus causing acute undifferentiated fever. Eur. J. Clin. Microbiol. Infect. Dis. 2016, 35, 705-711. [CrossRef]

57. Mahajan, S.K.; Nm, S.B.; Singh, D.; Kanga, A.; Kaushal, S.S. Scrub typhus and leptospirosis co-infection in Himalayan region. Trop. Dr. 2012, 42, 176-177. [CrossRef]

58. Panda, P.K.; Mehta, V.; Bhasi, A.; Gupta, P. A coinfection of severe leptospirosis and scrub typhus in Indian Himalayas. J. Fam. Med. Prim. Care 2019, 8, 3416-3418. [CrossRef]

59. Borkakoty, B.; Jakharia, A.; Biswas, D.; Mahanta, J. Co-infection of scrub typhus and leptospirosis in patients with pyrexia of unknown origin in Longding district of Arunachal Pradesh in 2013. Indian J. Med. Microbiol. 2016, 34, 88-91. [CrossRef]

60. Das, B.K.; Mohanty, S.; Sahoo, P.K. Association of leptospirosis and scrub typhus in acute encephalitis syndrome in a tertiary care hospital in Odisha, India. Trans. R. Soc. Trop. Med. Hyg. 2021, 115, 1088-1090. [CrossRef] [PubMed]

61. Lee, W.-S.; Ou, T.-Y.; Chen, F.-L.; Hsu, C.-W.; Jean, S.-S. Co-infection with Orientia tsutsugamushi and Mycoplasma pneumoniae in a traveler. J. Microbiol. Immunol. Infect. 2015, 48, 121-122. [CrossRef] [PubMed]

62. Seow, C.W.-X.; Logarajah, V.; Tan, N.W.H. Typhoid and Scrub Typhus Coinfection in a Returned Traveler. Glob. Pediatric Health 2017, 4, 2333794X17726941. [CrossRef] [PubMed]

63. Princess, I.; Ebenezer, R.; Ramakrishnan, N.; Nandini, S. Pulmonary nocardiosis and scrub typhus in an immunocompromised host. J. Glob. Infect. Dis. 2018, 10, 108-111. [CrossRef] [PubMed]

64. Sapkota, S.; Bhandari, S.; Sapkota, S.; Hamal, R. Dengue and Scrub Typhus Coinfection in a Patient Presenting with Febrile Illness. Case Rep. Infect. Dis. 2017, 2017, 6214083. [CrossRef] [PubMed]

65. Verma, N.; Sharma, M.; Biswal, M.; Taneja, S.; Batra, N.; Kumar, A.; Dhiman, R.K. Hepatitis E Virus Induced Acute Liver Failure with Scrub Typhus Coinfection in a Pregnant Woman. J. Clin. Exp. Hepatol. 2017, 7, 158-160. [CrossRef] 
66. Pathak, S.; Chaudhary, N.; Dhakal, P.; Yadav, S.R.; Gupta, B.K.; Kurmi, O.P. Comparative Study of Chikungunya Only and Chikungunya-Scrub Typhus Coinfection in Children: Findings from a Hospital-Based Observational Study from Central Nepal. Int. J. Pediatr. 2021, 2021, 1-6. [CrossRef]

67. Chandramohan, A.; Venkatesh, S.; Dhandapany, G.; Stephen, S. Scrub Typhus Co-infection in an Adolescent Girl with Varicella. Indian Pediatr. 2015, 52, 891-892. [CrossRef] [PubMed]

68. Iqbal, N.; Viswanathan, S.; Remalayam, B.; Muthu, V.; George, T. Pancreatitis and MODS Due to Scrub Typhus and Dengue Co-Infection. Trop. Med. Health 2012, 40, 19-21. [CrossRef]

69. Akiyama, Y.; Ishikane, M.; Ohmagari, N. Epstein-Barr virus induced skin rash in infectious mononucleosis. IDCases 2021, 26, e01298. [CrossRef]

70. Fedyanina, O.S.; Filippova, A.E.; Demina, O.I.; Zhuliabina, O.A.; Tikhomirov, D.S.; Filatov, A.V.; Chebotareva, T.A.; Kuznetsova, S.A. The Nature and Clinical Significance of Atypical Mononuclear Cells in Infectious Mononucleosis Caused by the Epstein-Barr Virus in Children. J. Infect. Dis. 2020, 223, 1699-1706. [CrossRef]

71. Jones, J.F.; Straus, S.E. Chronic Epstein-Barr virus infection. Annu. Rev. Med. 1987, 38, 195-209. [CrossRef]

72. Hirsiger, J.R.; Fuchs, P.S.; Hausermann, P.; Muller-Durovic, B.; Daikeler, T.; Recher, M.; Hirsch, H.H.; Erracciano, L.; Berger, C.T. Syphilis Reactivates Latent Epstein-Barr Virus Reservoir via Toll-Like Receptor 2 and B-Cell Receptor Activation. Open Forum Infect. Dis. 2019, 6, ofz317. [CrossRef] [PubMed]

73. Karrasch, M.; Herfurth, K.; Kläver, M.; Miethke, J.; Mayer-Scholl, A.; Luge, E.; Straube, E.; Busch, M. Severe leptospirosis complicated by Epstein-Barr Virus reactivation. Infection 2015, 43, 763-769. [CrossRef]

74. Watanabe, Y.; Mashimo, S.; Ichige, H.; Nagata, H.; Kojima, M. Scrub typhus mimicking the clinical course of infectious mononucleosis: A case report. J. Rural. Med. 2021, 16, 62-66. [CrossRef] [PubMed]

75. Hjalgrim, H.; Friborg, J.; Melbye, M. The epidemiology of EBV and its association with malignant disease. In Human Herpesviruses: Biology, Therapy, and Immunoprophylaxis; Arvin, A., Campadelli-Fiume, G., Mocarski, E., Moore, P.S., Roizman, B., Whitley, R., Yamanishi, K., Eds.; Cambridge University Press: Cambridge, UK, 2007.

76. Imad, H.A.; Phadungsombat, J.; Nakayama, E.E.; Suzuki, K.; Ibrahim, A.M.; Afaa, A.; Azeema, A.; Nazfa, A.; Ahmed, A.; Saeed, A.; et al. Clinical Features of Acute Chikungunya Virus Infection in Children and Adults during an Outbreak in the Maldives. Am. J. Trop. Med. Hyg. 2021, 105, 946-954. [CrossRef] [PubMed] 